interpreting the pathology data; Ms J A Evans for statistical advice; Ms Maggie Shapland for help with computing; Dr J Golding for help with the study design; Dr D G White for supervising the collection of microbiological data; and $\mathrm{Mr} \mathrm{V}$ Orreffo and Mr D James for the microbiological analyses.

I Stanton AN, Downham MAPS, Oakley JR, Emery JL, Knowelden J. Terminal symptoms in children dying suddenly and unexpectedly at home. $\mathrm{Br} \mathrm{Med} \mathcal{f}$ 1978;ii:1249-51.

House of Commons Social Services Committee. Perinatal, neonatal and infant mortality. London: HMSO, 1988. (HC54.)

3 Watkins CJ. Can general practitioners prevent the sudden infant death syndrome? BrMed f 1989:298:1333-4.
4 Taylor MT, Emery JL. Family and community factors associated with infan deaths that might be preventable. BrMed $\mathcal{f}$ 1983;287:871-4.

5 Fleiss JL. Statistical methods for rates and proportions. Chichester: John Wiley, $1973: 80-2$

6 Cameron $\mathrm{MH}$, Williams AL. Development and testing of scoring systems for predicting infants with high-risk of sudden infant death syndrome in Melbourne. Aust Paediar f 1986;22(suppl 1):37-45.

Hoffman HJ, Damus K, Hillman L, Krongrad E. Risk factors for SIDS. Results of the National Institute of Child Health and Human Developmen SIDS cooperative epidemiological study. Ann NY Acad Sci 1988;533:13-30. 8 Wilson AD, Downham MAPS, Forster DP. Acute illness in infants: a general practice study. $\mathcal{F} R$ Coll Gen Pract 1984;34:155-9.

Spencer NJ. Parents' recognition of the ill child. In: MacFarlane A, ed. Progress in child health. Vol 1. Edinburgh: Churchill Livingstone, 1984:100-12.

(Accepted 28 February 1990)

\section{Synovium in AIDS: a postmortem study}

\section{A D A Dalton, J N Harcourt-Webster, A C S Keat}

Departments of

Histopathology and

Rheumatology, St

Stephen's Hospital,

London SW10 9TH

A D A Dalton, MRCPATH,

senior registrar in

histopathology

J N Harcourt-Webster,

FRCPATH, consultant

histopathologist

A C S Keat, MCRP, senior

lecturer in rheumatology

Requests for reprints to: $\mathrm{Dr}$ A D A Dalton, Department of Histopathology, Charing Cross and Westminster

Medical School, London SW1P 2AR.

BrMed f 1990;300:1239-40
Inflammatory joint disease has been reported in patients infected with HIV, some already with and others progressing to AIDS. ${ }^{1}$ Arthritis has been described as predominantly oligoarticular and asymmetrical, mainly affecting the joints of the leg, often the knee.

With the increasing numbers of people infected with HIV a better knowledge of the likely changes in the synovium of major joints, especially those of the leg, would considerably help in the management of these patients. We describe the histopathology of synovium removed from the knee at necropsy on patients with AIDS.

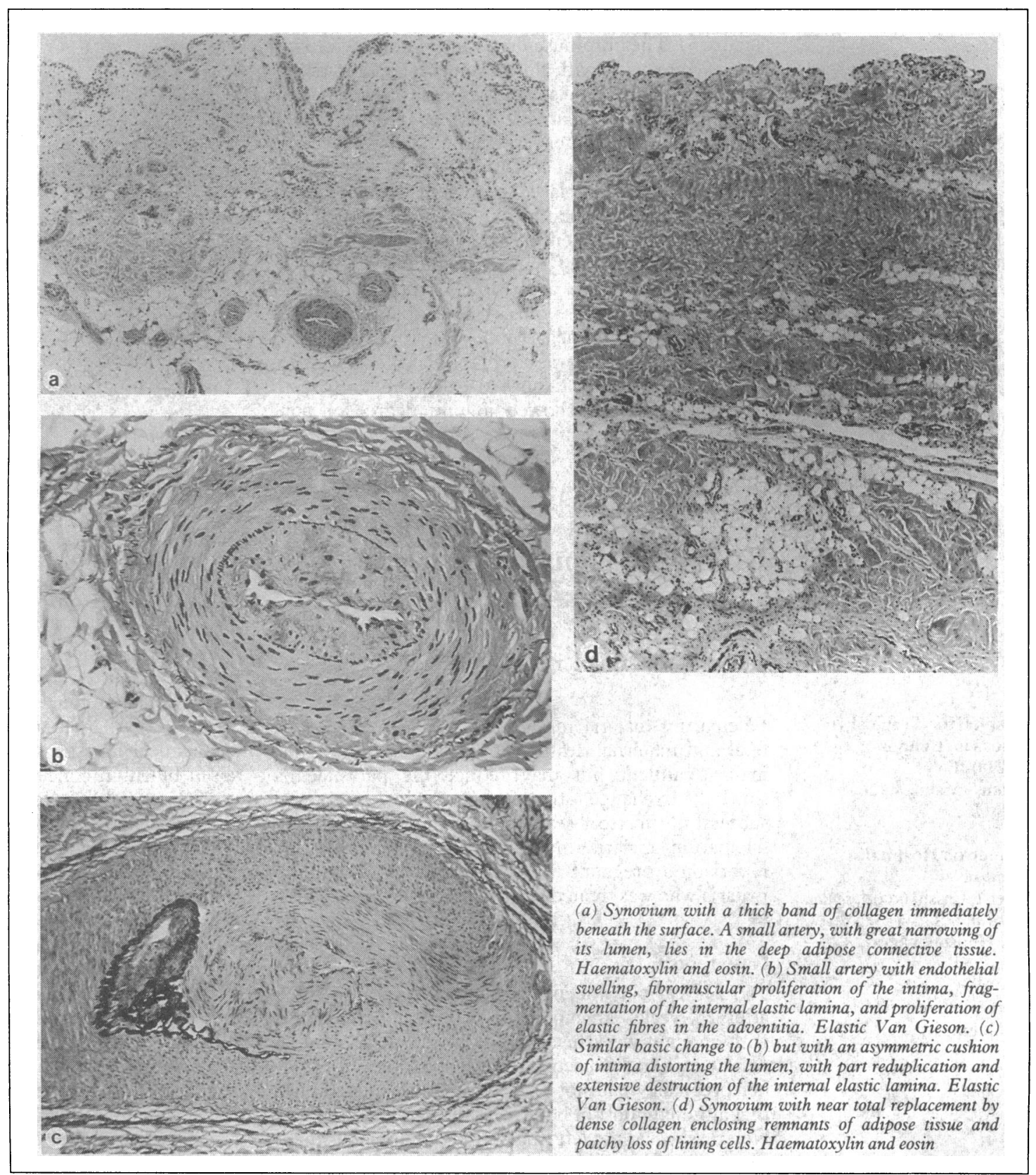




\section{Methods and results}

Necropsy was carried out on 25 patients ( 24 men, 1 woman) who died with AIDS in this hospital. The average age at death was 39.8 years (range 25-60), and none had any skeletal disease or joint symptoms. During necropsy three pieces of synovial tissue were removed from within the right knee cavity and examined using standard histological techniques, including those for elastic, bacteria, fungi, and acidalcohol fast bacilli. Similar control tissue was removed at necropsy from 12 other patients ( 7 men, 5 women) aged 20-88 years (mean 55.9) and processed in the same way. These had died of other causes, including suicide in an otherwise healthy person, and four were known to have osteoarthritis in the right knee.

Each fragment of synovium from the patients with AIDS showed abnormalities. Nineteen showed focal thinning and sometimes loss of the lining synovial surface; immediately underneath and running parallel was a band of collagen, either continuous or interrupted, but occupying at least half of the synovial surface area (see figure $a$ ). In continuity were thick bands of collagen traversing the deep lying adipoconnective tissue. Within the tissue were small arteries which showed endothelial swelling, fibromuscular proliferation of the intima, fragmentation or reduplication of the internal elastic lamina (or both), and proliferation of the elastic fibres in the adventitia (figure $b$ ). The fibromuscular change in the intima was often symmetrical with almost complete obliteration of the lumen, but was sometimes asymmetrical, producing a cushion of intima bulging into the lumen (figure $c$ ). Three further cases showed extensive loss of cells from the synovial surface, while the entire synovium was almost replaced by dense, poorly cellular collagen (figure $d$ ); the arteries were as before. The remaining three patients had a normal surface with only a mild degree of fibrosis in the synovium; the arterial findings were as before. There was no other abnormality in any case and searches for organisms and neoplasia produced negative results. In all the joints the cartilage surface was normal. The synovial tissue from the controls was normal except in those with osteoarthritis, who showed a mild degree of noninflammatory fibrosis.

\section{Comment}

The abnormalities found in these patients-namely, fibrosis attributed to ischaemia from the specific changes in the small arteries-seem to be unique to the synovium in AIDS.

The structure of normal synovial tissue is well described ${ }^{2}$ and its importance in the processes of joint disease is clear. ${ }^{24}$ Brewerton emphasises that a joint, regarded as part of the reticuloendothelial system, is particularly vulnerable to invasion by foreign substances and states that the vascular endothelium is the critical barrier between the rest of the body milieu and the joints. ${ }^{5}$ In joint disease, although a single disease can sometimes be induced by one agent, several different agents are probably more often implicated. In these patients with AIDS the initial insult to the synovium, probably HIV inspired, is likely to be modified by other factors such as the degree of immune suppression.

These joint changes are serious for all patients with AIDS. The histological findings are those of a greatly accelerated aging process in a predominantly young population developing over a short period. Premature aging is an external hallmark of established AIDS and, together with all the other known features, we believe that there is a greatly increased likelihood of potentially disabling degenerative joint disease.

We thank the clinicians of both St Stephen's and the Middlesex Hospitals who have allowed us to study their patients; Mr A J Hall, Mr P Mooney, and Mr D Webber for invaluable technical help; $\mathrm{Mr} \mathrm{M}$ Nelson for photomicrography; and Mrs K Burnett for help with researches and the preparation of the manuscript.

1 Rowe IF, Forster SM, Seifert MH, et al. Rheumatological lesions in one hundred and twenty three individuals with human immunodeficiency virus infection. Qf Med 1989;73:1167-84.

2 Edwards JCW. Synovial structure and function. London: Arthritis and Rheumatism Council, 1988. (Reports on Rheumatic Diseases series 2, No 8.) Gardner DL. The pathology of rheumatoid arthritis. London: Edward Arnold, 1972.

4 Fell HB, Jubb RW. The effect of synovial tissue on the breakdown of articular cartilage in organ culture. Arthritis Rheum 1977;20:1359-71.

5 Brewerton DA. Causes of arthritis. Lancet 1988;ii:1063-6.

(Accepted 22 February 1990)

\section{Exchange transfusion for severe falciparum malaria in pregnancy}

\section{Adam S Malin, Peter L Cass, C N Hudson}

\section{Hospital for Tropical Diseases, London NW1 OPE \\ Adam S Malin, MRCP, registrar}

\section{Homerton Hospital, London \\ Peter L Cass, MRCoG, senior registrar \\ C N Hudson, FRCOG, consultant}

Correspondence to: Dr Malin.

BrMed F 1990;300:1240-1
Falciparum malaria in pregnancy is associated with fetal and maternal death. Intravenous quinine is the main treatment but may reduce the parasitaemia slowly. Exchange transfusion has been used successfully to treat severe and complicated cases of falciparum malaria in non-pregnant patients. ' We report on a pregnant woman with severe falciparum malaria who was treated with exchange transfusion.

\section{Case report}

A 21 year old woman of Nigerian origin presented after 26 weeks' amenorrhoea in her first pregnancy with an eight week history of non-specific abdominal pain, which had worsened over the previous 48 hours; her pregnancy had not been booked. She stated later that although most of her earlier life had been spent in Nigeria she had not left England for the previous three years.
On presentation she was delirious and unable to give a history. Her temperature was $39^{\circ} \mathrm{C}$. Examination confirmed signs of pregnancy, but findings were otherwise unremarkable. An abdominal ultrasound scan showed a single viable fetus equivalent to a 33 week gestation. Haematological investigations showed a haemoglobin concentration of $109 \mathrm{~g} / \mathrm{l}$, leucocyte count $9 \times 10^{9} / 1$, and platelet count $93 \times 10^{9} / 1$. Results of biochemical investigations were normal except for a raised bilirubin concentration of $82 \mu \mathrm{mol} / \mathrm{l}$. Clotting studies, a sickling test, and haemoglobin electrophoresis yielded normal results. Examination of urine showed large amounts $(3+)$ of blood, protein, and bilirubin. A blood film showed Plasmodium falciparum: one fifth of the erythrocytes contained parasites.

In the intensive care unit $600 \mathrm{mg}$ of quinine dihydrochloride was given as a four hour intravenous infusion every 12 hours. Four hours after the first infusion she had an exchange transfusion of seven units of blood and a transfusion of four units of fresh frozen plasma over five hours. She remained haemodynamically stable throughout the procedure, and there was no evidence of fetal distress. Moderate uterine activity resolved spontaneously.

Twelve hours after admission the patient was alert, her temperature was $37 \cdot 2^{\circ} \mathrm{C}$, and a blood film showed a 